Alberto Sánchez Álvarez-Insúa

Instituto de Filosofía, CSIC

\title{
INÉS PALOU: DOS NOVELAS Y UN SUICIDIO
}

Palabras clave: Inés Palou, novela española de postguerra, Carne apaleada, Operación Dulce, testimonio, exculpación

\section{Introducción}

No sabemos muy bien si su experiencia carcelaria cambió para mal la forma de ser de Inés Palou (Agramunt, Lérida, 1923 - Gelida, Barcelona, 1975) o si, por el contrario, eligió el delito como forma de vida con anterioridad. En cualquier caso, su primera novela, Carne apaleada, es, o pretende ser, una autobiografía exculpatoria. Sobre su biografía real algo nos dicen los textos que acompañan a la edición de sus obras:

Nació en una familia de clase media que pudo pagarle estudios de Comercio y Peritaje Mercantil. Su educación familiar fue la misma que solían recibir hace cuarenta o cincuenta años las hijas de buena familia. Desempeñó diversos oficios relacionados con sus estudios hasta que siendo responsable en parte de la marcha financiera de una empresa se vio envuelta en problemas fiscales. Para salir del paso recurrió a métodos que la justicia consideró delictivos, por lo que pasó una larga temporada en la cárcel de mujeres de Barcelona. Allí comenzó a escribir. Y allí comenzaría también el terrible túnel de humillaciones y rebeldía del que sólo salió con el suicidio en 1975.

La historia que Inés Palou nos cuenta en Carne apaleada es una parte importante de su atormentada y propia historia de mujer rechazada, maldita. Pero es, además, la denuncia, autentificada con su vida posterior y con su muerte, de las condiciones inhumanas a que, a veces, se ven sometidas las personas a quien la sociedad juzga poco dignas de vivir en libertad.

Su obra póstuma, Operación Dulce, vuelve al mundo del delito, con el relato de un atraco, visto desde dentro, como ella ha visto durante tantos años a los seres que la sociedad rechaza. En la carta con que Inés Palou ofrecía esta última obra a sus editores, exponía las razones de su suicidio y legaba sus derechos de autor a su hija ${ }^{1}$ y a su íntima amiga, con quien compartió los últimos años. C. Ayala².

Inés Palou estudió Comercio y Peritaje Mercantil. Ambos títulos habilitaban para ejercer tareas de contabilidad y a ellas hubo de dedicarse Inés Palou en una fábrica de harinas. Eran tiempos de estraperlo bajo la displicente y corrupta mirada del Servicio Nacional del Trigo y Comisaría de Abastecimientos y Transportes ${ }^{3}$. Es en este mundo de

1 Hay un error. Inés no tuvo ninguna hija. La niña era de su amiga.

2 Inés Palou: Carne apaleada (Barcelona: Círculo de Lectores, 1976) e Inés Palou: Carne apaleada (Barcelona: Círculo de Lectores, 1977) pp. 269-270.

3 Sobre dicho tema cabe consultar: Dionisio Martín: El futuro de la Agricultura Nacional-Sindicalista. Programa rural de F.E. de las J.O.N.S. (Valladolid: Afrodiso Aguado, [1937]). En dicho folleto Dionisio Martín Sanz, Presidente de la Comisión central de Agricultura de F.E. de las J.O.N.S. responde a un cuestionario presentado por el Delegado del Ministro de Agricultura Alemán, Cristoph Barón Von der Kopp. El opúsculo comienza con una cita de José Antonio Primo de Rivera y sigue con las siguientes expresiones del citado don Dionisio: 
estraperlo y corrupción donde Inés Palou, se inicia en el delito. Luego seguirá acumulando estafas y cheques sin fondo que le harán dar con sus huesos en la cárcel y, finalmente, para no volver a prisión, poner fin a su vida en septiembre de 1975 arrojándose al paso del tren ${ }^{4}$.

\section{La primera novela: Carne apaleada}

En abril de 1975 la editorial Planeta publica la primera edición de Carne apaleada ${ }^{5}$ que acumularía hasta tres ediciones más, la última coincidiendo con la exhibición de su adaptación cinematográfica ${ }^{6}$.

La novela estructura sus 323 páginas en XLI capítulos muchos de los cuales se subdividen en dos y hasta tres subcapítulos. Está narrada en primera persona y se desarrolla,

¡Campesinos! ¡labradores

Para corregir es imprescindible conocerse

¡NOSCETE IPSUM!

¡Conócete a ti mismo!

Al final se incluye una circular y ficha repartida a todos los pueblos conquistados ( $\mathrm{sic}$ ). La encuesta inventario debía ser contestada, pueblo a pueblo y firmada por: El Jefe local de FE de las JONS, El Alcalde, El Secretario, El Maestro Nacional y el Sr. Cura Párroco.

Otro opúsculo del mismo tenor se editó en las mismas fechas: Dionisio Martín: El problema triguero y el nacional sindicalismo (Valladolid: Artes Gráficas Afrodisio Aguado, [1937]). El mismo da comienzo con una cita de Francisco Franco: «Se devolverá al agro, para mejorar la vida campesina, parte de lo que hoy absorbe la ciudad, en pago a sus servicios burocráticos y comerciales». Continúa con la trascripción del punto noveno de la Falange. Ya en el texto, don Dionisio hace, entre otras, la siguiente afirmación: «España debe producir el trigo necesario para su consumo y nada más que lo estrictamente necesario» (p. 21). El texto es la trascripción de la ponencia 20/6/1937 Bases para la solución del programa triguero presentada por Mariano Rodríguez de Torres y Dionisio Martín Sanz.

Sobre la política agraria franquista puede consultarse: Miguel Ángel del Arco: Las alas del Ave Fénix. La política agraria del primer franquismo (1936-1959) (Albote, Granada: Comares, 2005) capítulo 3.

Servicio Nacional del Trigo: Fábricas de harinas: normas para la adquisición, almacenamiento y venta de los distintos productos, así como pata la contabilidad de los mismos (Cuenca; Imp. de Falange, 1945).

Servicio Nacional del Trigo: veinte años de actuación (Madrid: Tall. De Blass, 1959).

La política agraria inicial del franquismo fue dubitativa. Trató, desde luego, de realizar la contrarreforma agraria, devolviendo las tierras a sus anteriores propietarios, pero procurando que todo el edificio productivo no se viniera abajo (Decreto de 28 de Agosto, BOE del 30, de 1936)

En su afán de controlarlo todo el bando sublevado legisló incluso sobre el hambre. La Orden de 30 de Octubre de 1936 (BOE del 3 de noviembre) creó «el día del plato único», 1 y 15 de cada mes para hoteles y restaurantes que debían entregar un porcentaje del coste de cada comida para fines benéficos, a fin de que «no quede ningún ciudadano sin su alimento diario y recoja en su seno a los huérfanos para hacer de ellos hombres amantes de Dios y de su Patria». Conjugar tal disposición con el cumplimiento cuaresmal era tarea obligada en un estado teocrático integrista, lo que se llevó a cabo en la Orden de 16 de Julio de 1937 (BOE del 21), el viernes pasó a ser el día de plato único y el lunes el día semanal «sin postre». Para más información consultar a L. M ${ }^{a}$ Ribó Durán: Ordeno y mando. Las leyes en la zona nacional (Barcelona: Bruguera, septiembre 1977).

4 O tumbándose sobre ellas. Esta última opción, tumbada no de través, sino sobre un único rail, fue la elegida por Inés que se suicidó situándose a la salida de una curva, para no ser detectada por el conductor del tren.

5 Inés Palou: Carne apaleada (Barcelona: Planeta, abril 1975) Colección Autores españoles e hispanoamericanos.

6 Inés Palou: Carne apaleada (Barcelona: Círculo de Lectores, 1976). La versión cinematográfica ha sido estudiada en un trabajo previo: Inés Palou: dos novelas, un suicidio y una película. IV Seminario del Grupo de Investigación Escritoras y Escrituras «De lo sagrado y de lo profano: mujeres tras/entre/sin fronteras»

Inés Palou: Carne apaleada (Barcelona: Círculo de Lectores, 1977)

Inés Palou: Carne apaleada (Barcelona: Planeta, 1978) Colección Popular. 
en su núcleo fundamental a partir de mayo de 1968, cuando la autora es detenida por primera vez, y su segunda caída en 1970. Ella misma nos lo dice al referirse a su condena: «mancillar la fama de quien durante cuarenta y siete años de su vida procedió decente y honradamente». (Capítulo XVIII, p. 142)7. Empieza con una dedicatoria:

\author{
A SENTA... \\ que al entrar en mi vida, \\ la fuente tornó río; \\ la ceniza, brasa viva; \\ y en el latir de mi sangre \\ puso un trote \\ de Pegasos desbocados. \\ Donde se encuentre... \\ ¡Dios la proteja!
}

En la segunda advocación nos dice:
«CUL DE PRESÓ...»
$[\ldots]$ benditas sean, don se encuentren, todas aquellas mujeres que se llamaron
Pili, Juanita, la Cuartero, Trini, Fifí...
y otras cuyos nombres no recuerdo,
y otras que nunca he conocido...

Pero que siguen sufriendo en cualquier cárcel, enmarcadas tras las rejas por gruesos muros, soportando lo insoportable.

Ambas dedicatorias resumen de alguna manera la novela que comienza con una frase evangélica: «Y cuando os hayan entregado...» (San Mateo, 10, 26-28). En este primer capítulo Inés nos narra su nueva detención. Ha intentado si éxito conseguir unas joyas en unos pequeños establecimientos de provincias, que la autora siempre identifica con su ini$\mathrm{cial}^{8}$, L. en este caso, pagando con cheques sin fondos. Luego revenderá la mercancía.

Es a partir del capítulo II, «1968. La puerta del infierno», cuando la autora da marcha atrás y nos narra, más o menos linealmente su historia. En el siguiente, «La primera piedra», Inés nos habla de su trabajo en una fábrica de harinas como contable bajo el control del Servicio Nacional del Trigo y Comisaría de Abastecimientos y Transportes ${ }^{9}$. Veamos lo que nos dice al respecto:

7 Tanto en Carne apaleada como en Operación Dulce se cita siempre por la primera edición. Al haber nacido la autora en 1923 la indicación nos sitúa en 1970.

8 Este planteamiento se mantiene a lo largo de toda la novela, tal vez para evitarse problemas, sobre todo al hablar de las cárceles que describe. Sin embargo, muchas son fácilmente identificables.

9 Aunque los tiempos más notables del estraperlo habían quedado atrás al finalizar los años 50 , el 15 de junio de 1952 desaparecen los cartillas de racionamiento de los artículos de primera necesidad: pan, azúcar, aceite, legumbres, etc., la picaresca en torno al trigo y a la harina seguían teniendo lugar ahora ya bajo la forma de fraude fiscal. 
Se molturaba más trigo del autorizado, se compraba trigo directamente al agricultor, se vendía la harina clandestina para enjugar esas compras también clandestinas, etc. Este sistema de clandestinidad continua daba lugar a un sistema contable especial. Era necesaria una contabilidad doble. (p. 25).

La situación se resolvía de la forma más simple, sobornando al inspector. Inés va, por causa de esa doble contabilidad, a la cárcel y allí, nos dice, se pone de parte de los desheredados. Y cita a Maeterlink: «intentaré hacer algo para que no lloren». Podemos decir que la protagonista, es decir, la autora, descubre al otro entre los muros de la prisión. Hay en toda la novela una insistencia en remarcar su altruismo.

El siguiente capítulo, el IV, «Dejad toda esperanza, vosotros los que entráis...» utiliza en su título la previsible frase de la Divina Comedia y narra los trámites de incorporación a la cárcel dirigida por una especie de monjas. De mucho más interés es el siguiente, «Sodoma y Gomorra», donde la prostitución y las relaciones sáfico-carcelarias hacen su entrada. El subcapítulo «Retratos en negro» se prolonga en el siguiente capítulo, el VI, que lleva el mismo nombre y viene precedido de una cita de Tagore: «Si de noche lloras por el sol no podrás ver las estrellas...» dos retratos se añaden a los anteriores, Françoise, la Heterosexual, absurda denominación pues el personaje es justamente lo contrario y el de «una pobre mujer, no una mujer pobre», ama de casa gallega a la que explota un jovencito. El capítulo no añade mucho pero nos sirve para conocer las lecturas de la autora, una miscelánea insólita sólo comprensible desde la óptica del 68: Marcuse, Miller, Rousseau y Tagore, a caballo entre la pedantería y el cursilismo. Los «retratos en negro» continúan con «El Gran Inquisidor» que no es otra que la Superiora de las monjas a cargo del penal. La cita, anónima, en este caso, nos dice: «Hay quien estudia a la gente, como el filósofo. Hay quien se la come, como el gastrónomo». Predicadora del infierno, trata de llevar a las reclusas a la moral: «Para esas monjas el delito sólo es condenable cuando es de índole moral: abandono de la familia, adulterio, prostitución, menores, etc.» (p. 53).

Aunque se trate de un retrato carcelario, la fórmula es perfectamente aplicable al nacional-catolicismo franquista, cosa nada rara, si se tiene en cuenta que España era, en 1968, una gran cárcel regida, precisamente, por el estamento eclesial.

La importancia del capítulo reside en que narra el primer encuentro de la protagonista con Senta, la Dulce, a la que va a dedicar el siguiente capítulo, el VIII, precedido por una frase sentenciosa, es de suponer que de su propia cosecha: «Amor no es dar, sino darse». Nos la describe como rubia y guapa, a sus veinticinco años. Madre soltera de una niña. Lesbiana. Está en la cárcel por asesinato de su amante, una mujer de cuarenta y cinco años a la que estranguló en el baño. Está condenada a veinte años. En el subcapítulo, «La muerte por vida», Senta explica que matar a su amante fue una liberación. En la realidad y en la narración Inés Palou se enamoró de ella sin importarle demasiado que tuviera las manos manchadas de sangre. Un amor que duraría toda la vida y la abocaría a la muerte.

«Gracias y no derechos» (Capítulo IX) con su frase de rigor: «El cordero y el tigre» describe como los presos son despojados de sus derechos, de su condición humana: 
Cuando una entra en la cárcel, pierde todos sus derechos. [...] dentro de la cárcel se pierden incluso los derechos humanos más elementales. El régimen penitenciario está montado sobre la base de un dirigismo total del recluso. Cualquier beneficio que éste pueda recibir, cualquier concesión que pueda obtener, jamás le es otorgada por derecho, sino por gracia. (pp. 67-68).

El subcapítulo «Luna de miel carcelera» nos narra la historia de un atraco. Algo que luego la autora desarrollará en su segunda novela, Operación Dulce.

E1 X capítulo está dedicado al recuerdo. «Un señor importante», es el jefe de la protagonista, procurador de las Cortes franquistas, que jugaba a la oposición domesticada, votando que no muchas veces. La autora nos describe como actuaba de «jefa de gabinete» y le escribía los discursos, que el ensayaba porque no sabía hablar. Su jefe no hace nada por ayudarla.

Berta, la protagonista-autora, es trasladada en el siguiente capítulo, «El éxodo», «... os llevarán de un lado a otro como animales...», nos dice. Berta hace amigos en el autobús penitenciario que la lleva hasta su tierra, Lérida.

De nuevo retratos, esta vez en «Gris y negro», del director de la cárcel, de la mujer de un médico que asesinó a su marido porque la engañaba, y de María, que da a luz en la cárcel y vende a la niña para pagar la fianza, de Pascualina, un homosexual que estrangula a otro recluso. Estaba en prisión por haber asesinado a su amante, y en la misma repite su hazaña matando a su nuevo amigo. Luego se va directamente a ver al cura para confesar lo que ha hecho:

—Ahí le tiene. Ya puede cantarle el réquiem. Lo necesitará. [...]

- Como el otro, igual que el otro. Todavía no ha nacido el hijo de perra que se ría de mí... Ahora ya tiene su merecido. Como el otro... como el otro... (p. 105)

Y de nuevo el amor, de nuevo Senta. Desconocemos si Inés tuvo experiencias homo y heterosexuales anteriores, pero su amor carcelario fue volcánico.

El capítulo XIV, «Noche de fuga», narra la evasión de tres reclusos. Dos lo consiguen, pero el otro se estrella contra el suelo y queda malherido. Luego narra la llegada de un transexual alemán. La han encerrado junto con su compañera por ofensas a la moral.

El siguiente habla de la relación de Berta con una presa política, una catalanista, cuyo delito era reclamar un obispo catalán para Cataluña, Monserrat trata sin éxito de que Berta abrace una causa justa.

El capítulo XVI viene precedido por una cita: «Le buscaba sentido a la vida, y tuvo que andar más allá de la muerte...».

Y nos habla de Michelle, una francesa drogadicta que ama las canciones de Edith Piaf, Georges Brassens y Charles Trenes, así como las poesías de Whitman y las novelas de Miller, y entre ellas, La pesadilla de aire acondicionada $(\text { sic })^{10}$. Es ecologista y ama el campo y la libertad. Finalmente acaba suicidándose.

${ }^{10}$ El título correcto es Pesadilla de aire acondicionado. 
Berta nos narra su juicio. Aunque sus perspectivas son favorables y su abogado excelente, los resultados son demoledores. La condenan a un conjunto de diez años. Una condena injusta:

Entonces -no tengo ningún miedo de repetirlo - era absolutamente inocente de los delitos que me acusaron. Después no. Por los delitos que he sido juzgada después no he sido inocente, sino culpable, plenamente culpable. [...] la primera piedra no tengo ningún reparo en afirmar que fue colocada en aquel juicio. Mejor dicho, la primera piedra fue el odio, el odio de quien, cegado por su avaricia y afán de dinero, no dudó en mancillar la fama de quien durante cuarenta y siete años de su vida procedió decente y honradamente. ( $\mathrm{p}$. 142).

El capítulo XIX, «El amor», abre con otra frase de la propia cosecha de la autora: «Un solo ser os falta... y todo está despoblado». Narra sus dificultades para ver a Senta, pero logra comunicarse con ella a través de otra reclusa. En el subcapítulo, «La locura», tras la frase de rigor: «La razón de los locos es, quizá, la única razón. La razón de nuestra comodidad nos impide aceptarla», cuenta como una de las reclusas tiene un ataque de locura. Ella logra calmarla pero las castigan a ambas. A Berta la ponen a fregar los pasillos.

Los dos capítulos siguientes, XX, «Los hombres y la Historia», y XXI, «La buena gente», abundan en citas de Brech. Berta recibe la bata carcelaria y la trasladan a la cárcel de Alcalá. Uno de sus compañeros de furgón, un chavalito, le da un beso para su novia y a Berta parece gustarle. También nos habla de una reclusa, Pauli, que es lesbiana y se la rifan entre todas. El XXII, «Horas grises», está de nuevo dedicado al amor. Senta le ha mandado un telegrama y ella es feliz. Rememora películas como Love story y Morir de amor.

«Retratos en negro», nos cuenta la historia de Pino, una chica de pueblo que envenena con arsénico a una familia entera... y a un perro. De esta última muerte es de la única que se arrepiente. La familia la explotaba, la maltrataba y casaron a su novio con otra. Por eso les mató. Pili era analfabeta. Y de nuevo el lesbianismo. Una de las celadoras, la señorita Trini, echaba la siesta con una reclusa. Un día alguien las encierran y se entera todo el mundo.

Los dos siguientes capítulos están dedicados a las presas políticas, «las de Burgos» haciendo alusión al conocido proceso del mismo nombre. Son de ETA y ponen bombas, le advierten las celadoras. Berta, no obstante, entra en contacto con ellas.

En el siguiente conocemos a dos mujeres pertenecientes a la nobleza. Una dice ser hija de Alfonso XIII y está en la cárcel por estafa. La otra es La Duquesa roja, es decir, la de Medina Sidonia. Concluye el capítulo reseñando que con motivo de la fiesta de Nuestra Señora de la Merced, patrona de los encarcelados, la visita un señor que ha leído sus artículos en Redención ${ }^{11}$.

${ }^{11}$ Se trata del semanario escrito por los reclusos y editado por el Patronato Central de Nuestra Señora de la Merced para la Redención de Penas por el Trabajo. Comenzó su andadura en 1939-40, junto a la editorial del mismo nombre y, según nuestras noticias, suspendió su publicación en junio de 1978. 
Dos temas componen el capítulo XXVI, un timo inmobiliario, algo parecido al caso Sofico, uno de los grandes escándalos del franquismo ${ }^{12}$, y otro el indulto dado por Franco con motivo del trigésimo quinto aniversario de su asunción del poder. Es octubre de 1971. Salen de Alcalá cerca de doscientas mujeres, pero a Berta no le alcanza.

Pero la imaginación todo lo puede. Al menos eso nos dice la autora al inicio del capítulo XXVII, «Navidades negras», «La imaginación es el pasaporte para superar la frontera de la desesperanza...». Berta monta la fiesta de Navidad, un Belén viviente con un lema: «Paz y amor», palabras que no hacen excesiva gracia a las celadoras. Pero al final lo consigue. De nuevo nos habla de lesbianismo, de dos amigas, Pepa y Pepita, a las que llaman La carta y El sello, porque van siempre pegadas y una tal Inmaculada, que lo no es, a la que llaman El Naranjo, condenada por atracos, que tenía múltiples «favoritas». Ella hará, en el Pesebre Viviente el papel de Tamborilero ${ }^{13}$. Berta nos informa de sus lecturas: Freud, Miller, Hesse, Whitman, Pavlov. Tan extraña miscelánea refleja sus inquietudes:

Me apasionada todo lo que hablara de sexo, erotismo, mecanismo y estímulos físicos que respondían a una determinada forma de ser humana. [...] Porque me encontraba asustada ante el cambio que en mí se operaba. [...] La homosexualidad simple, el lesbianismo, el amor, el sexo... ¿eran anormalidades o simples consecuencias de la condición humana que se encontraba reprimida? [...] ¿sería yo, en realidad, una lesbiana, una homosexual, una persona anormal sexualmente...? (pp. 224-225).

Berta consigue la excarcelación. Tiene todavía pendiente un sumario en Barcelona. Sale a la calle y comienza a trabajar con su antiguo jefe, pero la felicidad durará poco.

El capítulo XXIX, «La caída», narra su nuevo ingreso en la cárcel. ayudar a Senta. Todo se complica. No logra adaptarse al trabajo. Y su padre se suicida tirándose al metro. Delinque y es apresada. Pero se comporta hábilmente en el interrogatorio.

«Bajé a los infiernos como Orfeo», es el título del capítulo XXX. Berta ingresa en la cárcel de Murcia. De nuevo nos traza el retrato de las otras reclusas, Maruja, una gorda repugnante, La Pernales, mendiga profesional, presa por robar un bolso. Conoce allí a Antonia, una buena mujer que está encerrada por apropiación indebida, cuan el responsable era su jefe, un recaudador de contribuciones. Antonia era una secretaria fiel, y «pagó el pato». A Berta la mandan a Madrid, para el juicio, a Carabanchel. Allí conoce, en el capítulo siguiente a Caridad, «un sol de chica que amaba el riesgo». Cari está enamorada y manda a su novio cartas de amor, que le crean problemas cuando se las descubre. Ella vivía con un hombre, «El Oriental» que la llenaba de regalos. Es importante señalar que este último y la propia Cari serán los personajes de la segunda novela de Inés, Operación Dulce.

\footnotetext{
12 A raíz de la subida al poder de los tecnócratas tuvieron lugar numerosos escándalos financieros. Los más sonados fueron el caso Matesa, y el caso Sofico. En 1974, una sociedad dedicada a la construcción y venta de apartamentos turísticos, sobre todo en Estepota, quebró y dejó en la estacada a más de 25.000 accionistas. Sus directivos eran, en su mayoría, miembros del Opus Dei. Para más información, consultar: J. Castellá-Gassol. El libro negro de Sofico (Barcelona: Dopesa, 1975) y Jesús Ynfante: Los negocios ejemplares: Matesa, Sofico, los negocios del «Caudillo», Rumasa (Toulouse: Monipodio, 1975).

13 En clara alusión a la famosa canción de Raphael.
} 
El capítulo XXXIII está dedicado a la prostitución. «Las chicas de alterne». El mundo de las cantautoras antifranquistas tampoco está ausente de la novela. Aparece Isa, que canta con su guitarra «Ese tiempo se va a acabar...» $\mathrm{y}$ «Tu amor no es el final... tu amor no es el final... el final es lo otro...los otros...» a la autora le cae mejor que las otras presas políticas, tal vez porque le habla de cosas que le llegan al alma. De nuevo la galería de tipos: La Lutera pariente de El Lute acompaña a Berta de regreso a M. Y allí, la mala noticia: el fiscal pide para ella dieciocho años de cárcel. Para volverse loca. Que es, precisamente, lo que Berta hace, fingirse loca; y consigue que el médico la reconozca y lo certifique. Se celebra el juicio. La sentencia llega. En dos meses estará en la calle. A partir de ese momento la novela pierde fuerza. La autora incide, una vez más, en sus digresiones, e insiste en contarnos el anecdotario de sus compañeras de infortunio.

En el capítulo XXXVII empieza un tira y afloja con Senta. Esta vive en un pueblo con otra mujer, Marta, de la que dice estar muy enamorada. Pero pronto, acompañada de su hija, se persona en casa de Berta. Y empieza el juego de la seducción que Berta nota enseguida:

Senta, enamorada hasta la exasperación de otra mujer, se encontraba junto a mí, las dos en la cama, en mi cama, y había empezado a acariciarme. [...] Yo, el cordero, era ya pura arcilla en sus manos. Ella, la gata astuta y dulce, era ardor entre mis brazos. (p. 301)

Lo que quiere Senta es que Berta le compre un apartamento. Se marcha, pero vuelve, para salir de noche, a emborracharse. Van a un restaurante donde escuchan «El tiempo pasará», de Casablanca. En el penúltimo capítulo y al volver del cine de ver El gran Gastby se encuentran a Marta en el apartamento. Las amenaza con un cuchillo. Y Senta, se va:

Senta se ha ido con Marta. Estoy sola otra vez. Quizá sea la soledad definitiva. Pero no importa. Mi misión es esperar. Hoy, mañana y siempre. Sin final. Porque Senta es mi amor. Y su amor es la flecha de mi tiempo. Sin norte ni calendario. Espera, espera crucificada. Eso es el Amor. (p. 318).

Aquí concluye la novela, porque el último capítulo, el XLI, «Carta abierta a una sociedad civilizada», es una recapitulación de su vida y una reflexión sobre la cárcel y la reinserción de los presos. De nuevo, Inés Palou nos habla de Dios:

Ese Dios que, pese a todo, es una necesidad para el hombre. Yo lo he encontrado en la cárcel. En el fondo de los corazones deshechos. Dios existe. Doy fe.

Una fe necesaria para seguir viviendo. Sin olvidar que dinero, amor y carne tornan al bien nacido en un despojo bastardo. (p. 323).

Carne apaleada no es, ni mucho menos, una gran novela, pero su interés radica en el testimonio que aporta: la experiencia carcelaria de la autora. Es, precisamente, su personalidad la que no permite cuajar una gran obra. Inés Palou carecía de la suficiente cultura literaria y, en cambio, tenía un buen cúmulo de prejuicios burgueses y una cierta propensión a la cursilería. Su obsesión auto exculpatoria se explicita en algunos extre- 
mos: Dios y el Amor, fundamentalmente. Tuvo el valor de confesar sus delitos y su condición homosexual ${ }^{14}$, pero no profundiza en la misma. Su visión del «otro» es distante y se le escapa la conclusión más obvia: el sistema carcelario ignora la condición humana del recluso y lo cosifica, degradándole. En esa medida es pura violencia de estado. Negar la humanidad del otro es la justificación de todas las violencias, de todos los crímenes, desde el homicidio a la depreciación de sexo, desde la violación al genocidio.

\section{Operación Dulce: la segunda novela}

En noviembre de 1975, cuando se publica la primera edición de su segunda y última novela, Operación Dulce ${ }^{15}$, Inés Palou llevaba más de dos meses muerta. Se había suicidado arrojándose al paso del tren. La obra tuvo una tirada de 10.000 ejemplares, y ese mismo mes, se realizó una segunda ${ }^{16} \mathrm{y}$ tras ella, una tercera ${ }^{17}$. Fue de nuevo reeditada por el Círculo de Lectores en $1976^{18}$. Es obvio que la muerte de la autora sirvió de reclamo para su venta, así como el hecho de su presentación al premio Planeta, quedando la tercera en la votación. La ganadora fue la obra de Mercedes Salisachs ${ }^{19}$, La gangrena ${ }^{20}$ Se han publicado, hasta fecha, veintiuna ediciones. El finalista fue Víctor Alba ${ }^{21}$ con su novela $E l$

${ }^{14}$ En unos momentos en los que la represión franquista castigaba duramente a los homosexuales. El 15 de julio de 1954 se publicó en el BOE una extensión de la Ley de Vagos y Maleantes de 4 de agosto de 1933, probablemente el texto legislativo más nefasto del periodo republicano. La extensión incluye como figura delictiva la homosexualidad (capítulo I, Art. $2^{\circ}$ y Capítulo III, Art. $6^{\circ}, 2^{\circ}$ ) que no aparecía mencionada en la Ley de 1933. En 1970, Ley 16/1970 de 4 de agosto de Peligrosidad y rehabilitación social, en su Art. $2^{\circ}$ declara el estado peligroso de los que «realicen actos de homosexualidad», a los que se condena a ser internados en un centro de reeducación y al extrañamiento. Sobre la represión en el periodo franquista de los homosexuales hay una gran bibliografía. Se pude consultar:

Arturo Arnalte: Redada de violetas: la represión de los homosexuales durante el franquismo. Prólogo de Jerónimo Saavedra; epílogo de Pedro Cerolo (Madrid: La Esfera de los Libros, 2003) y

L. Alonso Tejada: La represión sexual en la España de Franco (Barcelona: Luis Caralt, octubre 1977) Biblioteca Universal Caralt. Serie Testimonio.

El franquismo copió exactamente el tratamiento dado por la República a los «vagos, maleantes...y homosexuales», es decir, confinamiento en centros de corrección y regeneración. En 1935 el Casa de Trabajo de Alcalá de Henares, que antes había sido cárcel de mujeres y era denominada «La Galera», pasó a llamarse Casa de Trabajo para corrección y regeneración de Vagos y Maleantes. En su fachada podía leerse el siguiente rótulo: UN MUNDO APARTE. VAGOS Y MALEANTES. En mayo de ese año tenía 474 reclusos (Fuente: «Visita a la Casa de Trabajo de Alcalá de Henares» Semanario Crónica, 12 de mayo de 1935, Año VII, nº 187. Sin paginar.).

15 Inés Palou: Operación Dulce (Barcelona: Planeta, noviembre 1975) Colección Autores Españoles e Hispanoamericanos.

${ }^{16}$ Inés Palou: «Operación Dulce» $2^{\mathrm{a}}$ (Barcelona: Planeta, noviembre 1975) Colección Autores Españoles e Hispanoamericanos.

${ }^{17}$ Inés Palou: «Operación Dulce» 3a (Barcelona: Planeta, 1975) Colección Autores Españoles e Hispanoamericanos.

${ }^{18}$ Inés Palou: «Operación Dulce» (Barcelona: Círculo de Lectores, 1976).

${ }_{19}$ Mercedes Salisachs (Barcelona, 1916) Antes de recibir el premio había publicado diez novelas en Planeta, habiendo quedado finalista del premio en dos ocasiones, 1955 y 1973. Pudiera decirse que era una «autora de la casa». Siguió publicando en dicha editorial, además de en otras, como Plaza y Janés hasta la fecha. Su última novela, Reflejos de luna se publico en Planeta en 2005.

${ }^{20}$ Mercedes Salisachs: La gangrena (Barcelona: Planeta, 1975) Colección Autores Españoles e Hispanoamericanos.

${ }^{21}$ Pseudónimo de Pere Pagés Elies (1916-2003), escritor catalán militante del POUM y detenido tras la guerra civil. Se exilio luego primero a Francia y luego a México. En 1957 se trasladó a Estados Unidos donde fue profesor en las universidades de Kansas y Ohio. En 1974 volvió a España, donde publicó la citada novela y una serie de libros sobre el marxismo en Cataluña, el movimiento obrero y la resistencia antifranquista. En 1996 publicó sus Memorias. 
pájaro africano ${ }^{22}$, novela que entre 1975 y 1983 tuvo diez ediciones. La comparación de dichas ediciones de las tres obras indica que el fallo del jurado fue bastante justo. Se ha especulado que Inés Palou se suicidó al no obtener el premio. Necesitaba el dinero para pagar sus descubiertos y no volver a la cárcel. Siendo sin duda cierta esta apreciación no lo es menos que puso fin a sus días antes de que el jurado emitiera su fallo y que el editor Lara, en unas declaraciones a $A B C$, antes del mismo, dejó claro que existían tres finalistas entre los que se encontraba Operación Dulce. Fue probablemente su relación sentimental la que le llevó a endeudarse y precipitó el fatal desenlace.

Operación Dulce es la historia de un atraco. Algo de lo que la autora tuvo conocimiento en la cárcel. Con este tema compuso un relato estructurado en dos partes con un total de diez capítulos en su primera parte y cinco en la segunda. La trama policial es el estudio de cinco personajes y su relación entre ellos. Tras una reflexión sobre el tiempo, la autora va presentándolos uno a uno en el primer capítulo.

\subsection{Primera parte: «Veinticuatro horas»}

La autora, antes de dar comienzo a la narración nos explica el propósito de la obra: describir la actuación de los personajes que van cometer y atraco y sus vivencias personales.

\subsubsection{Los personajes}

«Era una chica dulce... se llamaba Caridad» es el retrato de una compañera de reclusión (ver capítulo XXX de Carne apaleada) que amaba el riesgo y compartía la vida con un delincuente, apodado El Oriental, otro personaje de esta novela. Ha bautizado la operación en alusión a la «dulce Cari»:

A las doce en punto «Operación Dulce», había dicho el Oriental. Al principio todos se rieron. Todos menos Caridad. Ella sabía que el Oriental la había bautizado así porque se le ocurrió cuando estaba haciendo el amor con ella. Le vino de repente. Como un tiro.

Él la llamaba dulce en aquellos momentos. La llamaba «Dulce» repetidamente. (pp. 10-11).

Dos consideraciones merece el párrafo anterior. La primera, de carácter estilístico, es el empleo por la autora de frases supercortas, que dan rotundidad al texto. ¿De dónde proviene ese estilo? Difícil averiguarlo, pero existen dos posibilidades. La primera una influencia azoriniana. La segunda, en el polo opuesto, una técnica repetidamente empleada por los autores de quiosco como Corín Tellado o Carlos de Santander. Es posible que en la cárcel la autora leyera ese tipo de novelas. En cualquier caso, el efecto conseguido no es, ni mucho menos, negativo.

La segunda cuestión es la obsesión de la autora por el amor y el sexo. Insistiremos más adelante en este aspecto.

${ }^{22}$ Victor Alba (Pere Pagés Elies): El pájaro africano (Barcelona: Planeta, 1975) Colección Autores Españoles e Hispanoamericanos. 
Otra obsesión de Inés Palou es el tema religioso. De su personaje nos dice:

Caridad no creía en Dios. Decía que todo eso eran paparruchas. Pero creía en santa Gema. Santa Gema era otra cosa. Santa Gema hacía milagros. (p. 11).

Notable confesión. Porque Caridad es Caridad, la compañera de infortunio, pero también Inés Palou, que vivía obsesionada por el amor y trataba de desvincularlo del sexo, de sublimarlo, tanto para adecuar el principio de placer a su realidad como para autojustificarse.

Y la mentalidad perversa de El Oriental algo tiene que ver con Senta, con «la dulce Senta», que, en el fondo sólo era un ser egoísta y desequilibrado. Alguien capaz de matar o de llevar al otro, a ella, a Inés Palou, hasta el suicidio.

Pero por encima de su locura, El Oriental era un genio para los atracos. Los planeaba a la perfección. Y no deja que ninguna mujer se le vaya si él no la deja ir. Caridad sabe que no puede abandonarle.

«Parecía un monje budista... le llamaban 'El Oriental'».

Este segundo subcapítulo insiste en la relación entre ambos personajes y va explicando, poco a poco, la mecánica del atraco planeado y sus actores, los otros personajes de la novela. Esta insistencia en explicar las relaciones entre Caridad y El Oriental resulta, a todas luces reiterativa.

«Era ingeniero y estaba desesperado. Se llamaba Rogelio en el carné de identidad».

Los siguientes personajes son Rogelio y Elisa. Son amantes y ella está dominada por el alcohol y los somníferos, pero sus grandes amores son Rogelio, por el que ha abandonado a su marido y a sus hijos, y su perrita Nina, una caniche enana. La autora nos explica todos estos extremos:

De nuevo la experiencia carcelaria ilustra a la autora, pues había conocido en prisión a mujeres que estaban allí por adulterio, lo que en el franquismo era delito ${ }^{23}$.

Rogelio es amigo de la infancia de Caridad, y ella le presenta al Oriental. Se suma al atraco. Es el único camino que le queda para que las cosas cambien.

«Era el cuarto hombre. Huía de la policía. Se llamaba Roberto. Había roto el carné».

A su vez Rogelio presenta a Roberto, un perseguido político amigo suyo a El Oriental. Sólo le queda esa salida para huir de España, donde está acabado. A Roberto sólo le preocupa la violencia. La evitó a toda costa en su militancia política.

Esta vinculación política-violencia es una característica del pensamiento de Inés Palou y proviene, tal vez, de su contacto en la cárcel con militantes de ETA. Aunque la propaganda franquista, que vinculaba, precisamente, política y violencia, cuando la mayoría

${ }_{23}$ El movimiento feminista y partidos como el PCE consiguieron arrancar a la derecha la despenalización del adulterio y la legalización de los anticonceptivos. Tras ambas conquistas sucederían la ley del divorcio y la de interrupción del embarazo. La Ley de 26 de mayo de 1978, derogó algunos artículos del Código Penal, entre ellos los delitos de adulterio y amancebamiento. La Ley de 7 de octubre de 1978 despenalizó los anticonceptivos. 
de los grupos opositores eran pacíficos, también debió influir en ella. Que la creyera no dice mucho en su favor, y revela, una vez más, que pese a su experiencia carcelaria Inés Palou era una burguesa al uso.

Rogelio ha presentado a Roberto y Caridad. Desde el primer momento, la autora deja claro que se enamora de ella: «A Roberto le inquietaron desde el primer día los ojos de Caridad [...] estaba convencido de que a Caridad le hubieran gustado sus versos. [...] No. No estaba bien que él pensara en Caridad. Aquella chica pertenecía a otro». (pp. 39-40).

«Era el hijo de la abuela Rafaela. Todos le llamaban Rafa».

Rafa es el último personaje del drama, un perro fiel de El Oriental que vive con su madre y es medio retrasado mental.

En realidad era la sombra del Oriental: era su guardaespaldas. Le seguía como un perrito. Mejor dicho, como un perrazo. Porque Rafa tenía un aspecto impresionante. Alto, gordote, todo un matón. [...]

Lo malo era que a Rafa lo traía de cabeza una mujerona del bar de Paco que se hacía la difícil. El no estaba acostumbrado a esa. Podía ser idiota, pero era todo un macho. Las mujeres del barrio se lo rifaban. (pp. 41-42).

A Rafa, que no gasta nada en él, le gustan las mujeres llenitas y no entiende como su amigo está tan loco por Caridad, tan delgada. Por consejo de su amigo se viste y se perfuma para la cita de «negocios» que el grupo de atracadores va a celebrar en un restaurante.

Esto da paso al siguiente capítulo:

\subsection{2. «Comida de negocios»}

Que está, como siempre, subdivido en varios apartados. El primero de ellos tiene carácter de presentación y sirve para dar paso a los siguientes en los que cada personaje elige un plato diferente, de acuerdo con su personalidad.

«Melón con jamón y Perelada rosado...» es el menú elegido por Caridad, que está impresionada por Roberto y por el amor de Rogelio y Elisa.

«Un Villagodio y Sangre de toro». Eso pidió El Oriental, al que preocupa la forma de Roberto de mirar a Caridad. Y siente envidia de la relación entre Rogelio e Isa. También le preocupa Rafa y su relación con la mujer del bar.

«Una paella para dos... y dos sangrías». Eso es lo que piden Rogelio y Elisa. Explican que tras el atraco irán a Suiza. Y Roberto a Casablanca. Pero esto último no es cierto. Roberto irá también a Suiza, con sus amigos, pero no quiere que El Oriental lo sepa.

«Riñones al jerez y Alella marfil». Tan suculenta comida es la que elige Roberto. Y de nuevo, su obsesión por Caridad. Quiere emprender una nueva vida, pero con ella.

«'Entrecôte’ con patatas y Rioja tinto». El último menú es el de Rafa. Y cuando empieza a comer, deja de pensar.

El siguiente capítulo explica la planificación del atraco. 


\subsection{3. «El plan. El qué, cómo y dónde del golpe»}

Ya en su casa, El Oriental explica su plan sobre un plano. Se trata de asaltar un furgón que traslada fondos a varios bancos. Aprovechando el momento en que en el mismo queda únicamente uno de los agentes de seguridad, mientras el otro, acompañado de un empleado no armado, entra en el banco llevando una saca, Rafa y El Oriental le atacarán y se apoderarán del resto de las sacas. Mientras, Caridad y Rogelio, que están en el banco fingiendo rellenar impresos, se encaminan a la salida y ella finge un desmayo, momento que aprovecha Roberto para desarmar al agente de seguridad y hacerse con la otra saca. Luego huyen todos en un coche conducido por Roberto. Caridad, Rafa y El Oriental se bajarán enseguida con el dinero y cambiarán de coche y de aspecto. Rogelio y Roberto abandonarán el coche enseguida y tomarán el metro. Luego se reunirán en casa de $E l$ Oriental para repartir el dinero, recoger la documentación e irse a aeropuerto.

\subsection{4. «A cada cual lo suyo»}

El alquiler de los coches, los disfraces, las maletas preparadas para ocultar el botín, la huida. No queda nada por programar. Habida cuenta que están fichados, El Oriental y Rafa tendrán una coartada. Irán a Barcelona con sus nombres reales y se dejarán ver allí el día antes. Volverán con nombres supuestos en avión, y tras el atraco volverán de idéntico modo a Barcelona, dejándose ver de nuevo. Todo el mundo creerá que no se han movido de allí. Luego, días más tarde, El Oriental se reuniría con Caridad en el aeropuerto de Lisboa.

«Operación Dulce» se había puesto en marcha.

«Camino de su apartamento «El Oriental» divagaba con aire de rito... cual si fuera un monje budista camino de la pagoda». El Oriental, camino de su apartamento, reflexiona sobre sus inicios, sobre los sabios consejos de primer jefe... y sobre Caridad.

«Equipaje de recuerdos». Rogelio e Isa están preparando su marcha. No deben dejar nada detrás que pueda identificarles. Si por él fuera no llevarían nada, salvo a Nina.

«Acaso fuera el amor». Roberto reflexiona sobre su papel en el atraco, y sobre el sentido de su vida, su afición a la lectura, su empeño en ser él mismo. Y sobre su ideal de mujer. Esto le lleva a Caridad. Y ella estará sola, porque El Oriental está en Barcelona.

Caridad abrió la puerta [...] sintió que le temblaban las piernas [...] sin saber cómo se encontró aferrada a su cuello. [...] Él empezó a besarla despacio, suavemente. [...] Sin prisa, sin apasionamiento, como si aquel encuentro no fuera el primero. Con la seguridad del que vuelve y se sabe esperado. Con la seguridad de que aquello se prolongaría más allá del reloj y del calendario... (pp. 112-113).

«El tercer ojo». El Oriental, en Barcelona, apuesta en las carreras de galgos. Y pierde, cosa en él inhabitual, y que no le hace ninguna gracia. Rafa, a su lado, trata de animarle con una frase hecha: «Desgraciado en el juego, afortunado en amores», lo que le enfada aún más. El Oriental está inquieto y encima Rafa le habla de cuernos. Pierde de nuevo. Camino del hotel se acuerda de los monjes budistas. Le gustaría tener un tercer 
ojo capaz de leer los pensamientos y ver las cosas a través de la distancia. Decide llamar a Caridad por teléfono.

«Como el vino rosado...». Caridad y Roberto se han dormido, uno en brazos del otro. Llama El Oriental por teléfono y parece que se queda tranquilo. Caridad se refugia en brazos de Roberto. «—Ayúdame, Roberto, ayúdame... si no me ayudas estoy hundida. Tengo miedo.

Y sus besos... sus besos la mecían en un dulce sopor tierno y cálido... como algo familiar... muy familiar. Como el vino rosado. Sí, como el vino rosado...» (p. 126).

El capítulo concluye ahí, con esa utilización excesiva de los suspensivos, algo que no es precisamente un prodigio estilístico.

\subsection{5. «Operación Dulce»}

«Empieza la cuenta atrás: Las ocho. Punto 5»

Son las ocho y Caridad debe tomar una ducha fría y ponerse en marcha. El Oriental ha debido de despegar ya de Barcelona. Debe quitarse el olor de Roberto que impregna todo su cuerpo, porque El Oriental sería capaz de detectarlo.

Entraría en el cuarto de baño. La besaría y, mojada y todo, se la llevaría a la cama en volandas. El Oriental era así. Siempre hacía el amor antes de dar un golpe. Decía que le traía suerte. [...] La puerta se abrió. [...] El Oriental avanzó sonriendo. Caridad abrió los brazos esperándole... (p. 131).

«Sigue la cuenta atrás: Las nueve. Punto 4»

Rogelio, cargado de maletas lleva a Isa y a Nina al aeropuerto. Le esperarán allí. A las doce, el atraco, y a las tres el despegue del avión para Suiza.

«Sigue la cuenta atrás: Las diez. Punto 3»

Acaba de llegar El Oriental. Rafa está disfrazado de chofer, cosa que no le hace ninguna gracia, y su jefe está irreconocible. Se ha disfrazado de señorito finolis, con peluca, sombrero y un bigote negro. Lleva una maleta con las armas. Dos metralletas y una pistola para Rogelio, además de la pistola que nunca se separa de El Oriental. Caridad sale del cuarto de baño a las once y pico. Impresiona al retrasado de Rafa:

«Sigue la cuenta atrás: Las once. Punto 2»

Roberto recoge a Rogelio en la Glorieta de Bilbao. Toman café y casi ni se hablan. Roberto está ansioso de contarle a su amigo lo de Caridad. Pero no lo considera oportuno. Las once y cuarto. Tienen que irse. Suben al SEAT 1430. Primera parada en Ayala, 30. Al lado del mercado de la Paz. Las doce menos cuarto. La operación está en marcha y todo está cronometrado.

«Sigue la cuenta atrás: Doce menos cuarto. Punto 1»

Frente al mercado aparca un lujoso Mercedes. El chofer abre la puerta. Una pareja elegante desciende y los tres entran en el mercado. Caridad, El Oriental y Rafa han dado 
comienzo a su papel en «Operación Dulce». El Oriental compra una docena de rosas rojas para Caridad y salen, tras cruzar el mercado, por la puerta lateral que da a la calle Ayala. Suben al 1430. a las doce menos cuarto paran delante del banco, en la calle de Velázquez. Bajan Caridad y Rogelio y entran en el banco.

(Lo minucioso de la descripción y el conocimiento de la geografía madrileña rebela que la autora estudió muy bien el tema y que una de las autoras del atraco debió contárselo en la cárcel de forma pormenorizada.)

«Termina la cuenta atrás: Las doce en punto. Punto 0»

Las doce en punto. Caridad no está nerviosa, pero sí excitada. Y está decidida a irse con Roberto y dejar a El Oriental. Ha entrado en el banco y ve llegar al furgón y como el policía de la metralleta y el empleado se dirigen a la puerta principal. Mira a Rogelio y se pone en marcha. Finge el desmayo y Rogelio desarma al policía y se hace con la saca. Corren hacia el coche. El Oriental está desvalijando el furgón. E pronto hay un tiroteo y Caridad escucha una ráfaga de ametralladora. Entra en el coche que arranca veloz, conducido por Roberto: «¿Qué ha pasado? — preguntó Caridad. Le he dado, le he dado...- - decía Rafa. Y se reía... Calla, idiota— le ordenó El Oriental». (p. 141).

Calles Velázquez y Ayala, donde descienden Caridad, El Oriental y Rafa. El coche sigue al paseo de la Castellana y Roberto y Rogelio, tras quitarse las pelucas y los bigotes y vaciar las sacas metiendo el dinero en dos maletas, lo abandonan. Cruzan y en Colón se meten en una cafetería a tomar café. Toman también conciencia de lo que ha pasado. El policía, además de la metralleta llevaba una pistola y ha estado a punto de matar a Caridad. La ráfaga de metralleta de Rafa, la ha salvado. Pero atrás queda el policía, tendido sobre la acera, tal vez muerto. Abrumados llegan a Alcalá y toman el metro.

Mientras, Caridad, El Oriental y Rafa han cruzado el mercado de la Paz y saludan a la florista. Luego, suben al Mercedes. Y ponen rumbo al apartamento. «Operación Dulce» ha entrado en la historia.

\subsection{6. «Dispersión de riesgos»}

«Los cuatro puntos cardinales»

Rafa está muerto de miedo. Miedo por lo que ha pasado y por estar en el avión, rumbo a Barcelona. El Oriental le promete que no le abandonará y menos ahora que ha salvado a Caridad. Antes, en el apartamento, han repartido el dinero: cinco millones cada uno.

«Operación Dulce» había terminado. Sus personajes iban cada cual a su destino.

La rosa de los vientos marcaba, uno tras otro, los puntos cardinales.

NORTE: Rogelio y Elisa. Iban a Suiza. SUR: Roberto. Tenía billete a Casablanca.

ESTE: El Oriental y Rafa. Su primer destino, Barcelona. OESTE: Caridad. Caridad tenía que ir a Portugal. Dispersión de riesgos. Cada cual a su destino. (p. 150). 


\subsection{7. «La resaca»}

«El color azul de la ilusión... se volvió rojo de sangre»

Rogelio está preocupado. Roberto y Caridad le han contado su relación. El necesita el apoyo de su amigo y sabe que El Oriental no es de los que perdonan. Tienen el dinero pero hay un hombre muerto. «Operación Dulce» ha cambiado de color: antes era azul y ahora tiene el color rojo de la sangre.

«La excitación del riesgo... se volvió escalofrío de miedo»

Roberto ha decidido irse con Rogelio y Elisa. Tenían al menos un día para despistar a El Oriental. Pero Caridad sabe que nunca va a sentirse segura. El Oriental la buscará hasta encontrarla.

\subsection{8. «La rosa de los vientos»}

«Marcaba el rumbo. Primero marcó Este». Elisa ha pasado, junto a Nina, todo el día en el aeropuerto. Piensa en sus hijos a los que ya no verá jamás. Sabe que El Oriental y Rafa tiene que tomar el avión a Barcelona. Anuncian el vuelo y, desde la cristalera, los ve bajar de autobús y subir al avión, que enseguida despega. La rosa de los vientos señala el Este.

«Siguió marcando Norte». Elisa mira el reloj. Rogelio se retrasa. Y El Oriental estaba pálido. Pero en el aeropuerto no hay ninguna anormalidad. Por fin aparece Rogelio, acompañado de Roberto y Caridad. Elisa comprende enseguida.

De pronto, todo cambia en el aeropuerto. Los controles se extreman. Pero Roberto y Caridad consiguen billete. Los inspectores les dejan pasar. La presencia de Nina es su salvoconducto: nadie sospecha de dos parejas que llevan una perrita faldera. El avión despega. La rosa de los vientos señala Norte. Rumbo a Zurich.

«Después... dejó de marcar». La rosa de los vientos ya no señala el resto de los puntos cardinales. Los aviones de Casablanca y Lisboa reclaman insistentemente por los altavoces a los dos pasajeros retrasados, pero nadie atiende y despegan sin ellos.

\subsection{9. «Captura y huida»}

«Los coletazos del tiburón herido». El Oriental se dispone a apostar en el canódromo. Allí estaba García, un policía al que conocía desde hacía años. Está preocupado por Rafa, que está nerviosísimo. Va a ventanilla por los boletos y García se dirige a Rafa: « —Oye, tú, ¿no estabas esta mañana en Madrid? ¿Cuándo has llegado?» (p. 168).

Rafa, horrorizado, huye, pero le cogen. El Oriental, al ver lo sucedido, escapa también pero con tranquilidad. Se quedará en Barcelona, en casa de Rosa, una antigua amante. Llamará a Caridad por teléfono, a casa de su madre.

\subsubsection{0. «Desesperación»}

«El amargo sabor del desengaño». El Oriental ha encontrado refugio en casa de Rosa. Son inútiles sus intentos de comunicarse telefónicamente con Caridad. El Oriental 
recela. Piensa en ella y en Roberto y le asalta la duda. Comprueba en control de vuelos que Roberto no ha tomado el avión de Casablanca.

A las tres de la tarde toma el avión para Lisboa. Nadie recela de un estudiante tailandés cargado de cámaras de fotos. El Oriental la ha emborrachado y ha asumido su personalidad. A las seis llega a Lisboa, pero Caridad no está ni ha dejado ningún aviso.

\subsection{Segunda parte: «Tiempo después...»}

En este conjunto de breves capítulos se nos da noticia de las consecuencias personales de todos y cada uno de los actores del drama. Pero la mejor explicación es dejar hablar a la propia autora:

En esta segunda parte se describe la vida de cada uno de los personajes de «Operación Dulce», una vez terminada ésta. Es lo que podríamos llamar la posthistoria, la consecuencia del hecho delictivo en cada uno de sus autores. (p. 179).

\subsection{1. «El botín de cada cual: Nostalgia»}

Rogelio recibe un telegrama de Roberto. Caridad ha tenido una niña. Isa, en cambio, ha visto frustrado su embarazo. Ya no podrá tener más hijos. Y no está bien de salud.

Han pasado diez meses. Y sienten nostalgia. Mucha nostalgia.

Han puesto un pequeño taller y se ganan la vida. Han recibido también la visita de El Oriental. El timbre sonó tres veces y apareció. Buscaba a Caridad. La buscaría hasta encontrarla. A Rogelio le pareció más loco que nunca. Más enamorado de Caridad que nunca. Con una sola obsesión: encontrarla y matarla.

El Oriental le explica la detención de Rafa. Le ha buscado un buen abogado, pero lo tiene muy mal. Está seguro que le van a condenar a muerte. El estuvo escondido unos meses en Portugal y tiene grandes proyectos:

Rogelio avisa a Roberto y a Caridad que estaban en París. Huyen a Londres. Junto con Isa vive su destino:

Ambos comprendieron que estaban definitivamente marcados. Llevaban consigo el lastre de un pesado equipaje de recuerdos.

«Operación Dulce» había tenido para ellos un sabor muy amargo.

Y el botín que les había correspondido tenía un triste nombre: NOSTALGIA.

\subsection{2. «EI botín de cada cual: Miedo»}

Caridad piensa en su hija y en El Oriental. Él nunca quiso tener hijos e incluso la hizo abortar. Se acuerda de los disparos. Del policía tumbado en la acera. Muerto. Piensa en la diferencia entre Roberto y El Oriental.

«Operación Dulce» también le había dejado un sabor amargo. Muy amargo. El botín que le había correspondido tenía un nombre de pesadilla, aterrador: MIEDO (pp. 195-196). 


\subsection{3. «EI botín de cada cual: Vergüenza»}

Roberto está nervioso. Muy nervioso. Lo tiene todo. Dinero, el amor de Caridad, una hija, pero no puede sustraerse a la vergüenza de haber traicionado sus ideales.

De nuevo la autora no entiende bien la militancia clandestina e insiste, una vez más, en vincular política y violencia.

Roberto quiere escribir, quiere crear. Dedicarse a su mujer ya su hija.

Aunque en medio de toda aquella herencia de amor y felicidad, que tenía para él el cálido sabor de los vinos rosados, «Operación Dulce» le hacía sentir un sabor amargo.

«El botín que le había correspondido tenía un feo nombre de: VERGÜENZA».

(p. 206).

\subsection{4. «El botín de cada cual: Odio»}

El Oriental tiene que actuar. Se plantea un secuestro político: «Operación Cónsul» ${ }^{24}$. Ha contratado a un alemán para que busque a Caridad y Roberto. La operación se lleva a cabo secuestrando al cónsul en plena calle. Para liberarlo exigen dinero y la liberación de los presos políticos. Para El Oriental, que se hace llamar ahora monsieur Bardoud, no hay problema, pero lejos de liberar al cónsul tras haber obtenido el dinero y la libertad de los prisioneros, lo asesina. Tras el secuestro, recibe información del alemán. La pareja estaba en París, pero ha volado. Han tenido un hijo, y el marido es escritor. Al Oriental sólo le queda esperar, rumiando su frustración y su odio.

Sintió que el rencor le recorría todo el cuerpo latiendo en sus venas.

«Operación Dulce» había tenido para él un sabor muy amargo.

El botín que le había correspondido tenía un nombre desesperado: odio. (p. 219).

\subsection{5. «EI botín de cada cual: Muerte»}

En la Audiencia están juzgando a Rafa. Han pasado diez meses y en la cárcel a aprendido a pensar. Rafa piensa en Rosario, la del bar, en El Oriental y en lo que le dice su abogado. Intentará conseguirle un atenuante por problemas mentales. A Rafa, que le digan que está loco no le hace ninguna gracia.

Pero la condena, claro está, es de muerte. Rafa no lo entiende muy bien. El cura le dice que tiene que prepararse. Y tampoco lo entiende. Finalmente llega la hora. Se desmorona cuando le dicen que tiene que morir. La autora nos narra la ejecución en el garrote vil:

Le pusieron una capucha negra en la cabeza. Sintió que le ponían algo alrededor del cuello. Quiso gritar. No pudo. Sentía como un nudo...[...]

Rezaría. El cura le había dicho que cuando llegara la hora rezara... En la cárcel había apren-

${ }^{24}$ La autora refleja el secuestro llevado a cabo por ETA en aquellas fechas, en concreto el del cónsul alemán Eugenio Behil, el 1 de diciembre de 1970. 
dido un poco a rezar...

Padre nuestro que est... Cra...gggggg.

Dejó de rezar.

El verdugo no le dio tiempo. La vuelta había sido definitiva.

Todo terminado.

«Operación Dulce» había tenido para él sabor más amargo para el pobre Rafa.

El botín que le había correspondido tenía un fatídico nombre: MUERTE. (p. 234).

La autora concluye la novela con una consideración final:

Aquí termina el relato de OPERACIÓN DULCE.

Pero sus personajes siguen su propia historia

andando por la vida con su botín a cuestas y

ante un futuro que es una incógnita para todos.

A CADA CUAL LO SUYO: EL DELITO JAMÁS

QUEDA IMPUNE

Hay que poner la palabra

FIN

Aunque la vida siga y la historia continúe... (p. 235).

Así concluye la novela. El paso por la cárcel dejó en la autora un síndrome de culpa que debe ser expiada. No es una gran novela, pero como la anterior, refleja perfectamente los sentimientos de la escritora y tiene un cierto contenido exculpatorio. La vida viene como viene, parece decirnos. El hombre es él y su circunstancia. Algo que Ortega afirmaba y que Sartre hubiera negado con toda rotundidad. No fue Inés Palou una gran escritora, pero no puede negársele su capacidad narrativa. De haber vivido más tiempo habría, sin duda, perfeccionado su estilo, y podía haber tenido un sitio entre la pléyade de escritoras españolas del siglo XX. Por decisión propia no lo quiso así. Entró a formar parte del grupo de personas que deciden que no pueden ni quieren seguir viviendo $\mathrm{y}$, voluntariamente, nos abandonan para siempre.

\section{BIBLIOGRAFÍA}

Alba, V. (Pere Pagés Elies) (1975): El pájaro africano. Barcelona: Planeta, Colección Autores Españoles e Hispanoamericanos.

Arco, M. Á. del (2005): Las alas del Ave Fénix. La politica agraria del primer franquismo: 19361959. Albote, Granada: Comares.

Arnalte, A. (2003): Redada de violetas: la represión de los homosexuales durante el franquismo. Prólogo de Jerónimo Saavedra; epílogo de Pedro Ceroso. Madrid: La Esfera de los Libros.

Castellá-Gassol, J. (1975): El libro negro de Sofico. Barcelona: Dopesa.

Martín, D. (1937): El futuro de la Agricultura Nacional-Sindicalista. Programa rural de F.E. de las J.O.N.S. Valladolid: Afrodiso Aguado. 
Palou, I. (1975): Operación Dulce. Barcelona: Planeta, Colección Autores Españoles e Hispanoamericanos.

Palou, I. (1975): Carne apaleada. Barcelona: Planeta.

Palou, I. (1976): Carne apaleada. Barcelona: Círculo de Lectores.

Palou, I. (1977): Carne apaleada. Barcelona: Círculo de Lectores.

Palou, I. (1978): Carne apaleada. Barcelona: Planeta, Colección Popular.

Ribó Durán, L. Ma (1977): Ordeno y mando. Las leyes en la zona nacional. Barcelona: Bruguera.

Salisachs, M. (1975): La gangrena. Barcelona: Planeta, Colección Autores Españoles e Hispanoamericanos.

Tejada, A. L. (1977): La represión sexual en la España de Franco. Barcelona: Biblioteca Universal Caralt, serie Testimonio.

Ynfante, J. (1975): Los negocios ejemplares: Matesa, Sofico, los negocios del «Caudillo», Rumasa. Toulouse: Monipodio.

VV. AA. (1945): Fábricas de harinas: normas para la adquisición, almacenamiento y venta de los distintos productos, así como para la contabilidad de los mismos. Servicio Nacional del Trigo. Cuenca: Imp. de Falange.

VV. AA. (1959): Veinte años de actuación. Servicio Nacional del Trigo. Madrid: Taller De Blass.

\section{INÉS PALOU: DVA ROMANA IN SAMOMOR}

Ključne besede: Inés Palou, španski povojni roman, Carne apaleada (Pretepeno meso), Operación Dulce (Operacija Ljubica), pričevanje, oprostitev krivde

Življenje Ines Palou (Agramunt, Lérida, 1923 - Gelida, Barcelona, september 1975) je pogojevala zaporniška izkušnja, prav tako njena dva romana, še posebej prvega, Carne apaleada (Pretepeno meso), ki je hkrati pričevanje o določenem času in njena avtobiografija, s katero se želi oprati krivde. Zdi se paradoksalno, da je Inés Palou prav njena osebnost preprečevala postati velika pisateljica, saj je zagovarjala skoraj vse malomeščanske predsodke in kazala nagnjenost $\mathrm{k}$ afektiranosti. Njena obsedenost $\mathrm{z}$ oprostitvijo krivde vodi k takšnim pojmom, kot sta Bog in Ljubezen. Čeprav je imela toliko poguma, da je priznala svojo istospolnost, se literarno $\mathrm{v}$ to tematiko ni poglobila. Njeno razumevanje sočloveka je oddaljeno, pri čemer se ji izmika najbolj očitno dejstvo: v zaporu se ne ukvarjajo s človeško naravo zapornikov, saj jih z degradiranjem spreminjajo v objekte. Pri tem gre za čisto nasilje države. Negiranje človeškosti v sočloveku je opravičevanje nasilja in vsakega zločina, tako umora kot posilstva ali genocida. Žrtev teh nasprotij je na koncu naredila samomor prav v času, ko je Španija vstopala v novo zgodovinsko obdobje in je za sabo pustila dolgo frankistično noč. 